\title{
Erratum to: Initiation of Stress Corrosion Cracks in X80 and X100 Pipe Steels in Near-Neutral pH Environment
}

Jidong Kang, Wenyue Zheng, Darren Bibby, Babak Shalchi Amirkhiz, and Jian Li

Erratum to: JMEPEG (2016) 25:227-240

DOI: 10.1007/s11665-015-1822-5

Please note that for Fig. 14 in this article as published the same photo is mistakenly given as is correctly given for Fig. 16.

Below is the correct photo for Fig. 14.

The online version of the original article can be found under doi: 10.1007/s11665-015-1822-5.

Jidong Kang, Wenyue Zheng, Darren Bibby, Babak Shalchi Amirkhiz, and Jian Li, CanmetMATERIALS, Natural Resources Canada, 183 Longwood Road South, Hamilton, ON L8P 0A5, Canada. Contact e-mail: jidong.kang@canada.ca. 


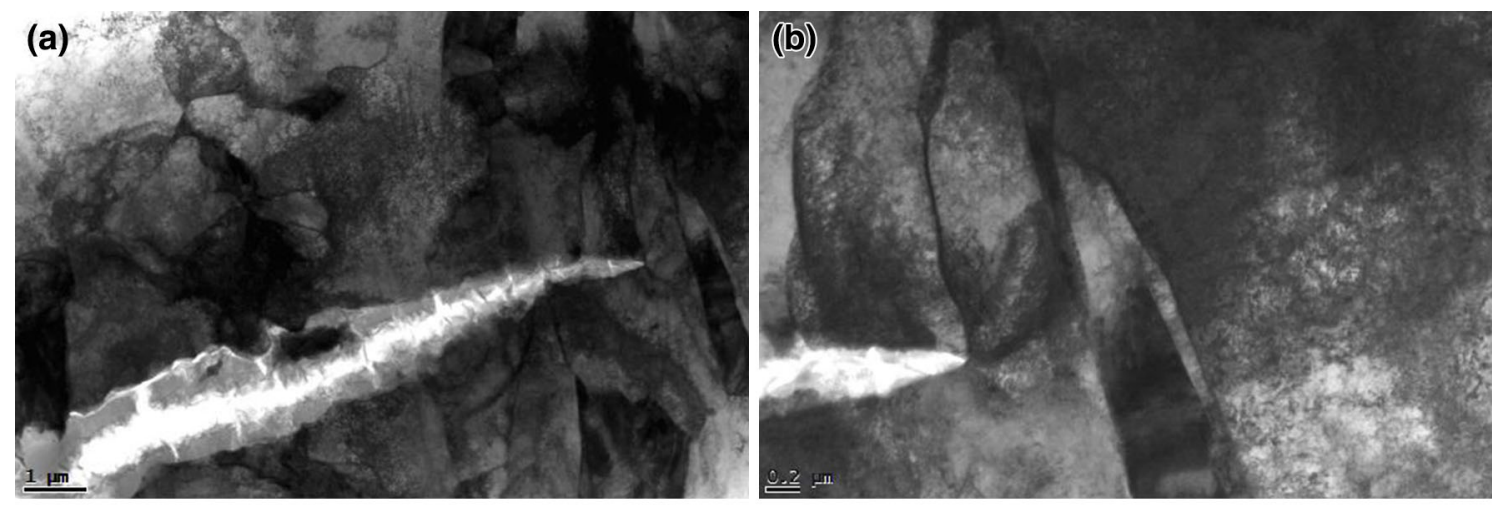

(c)

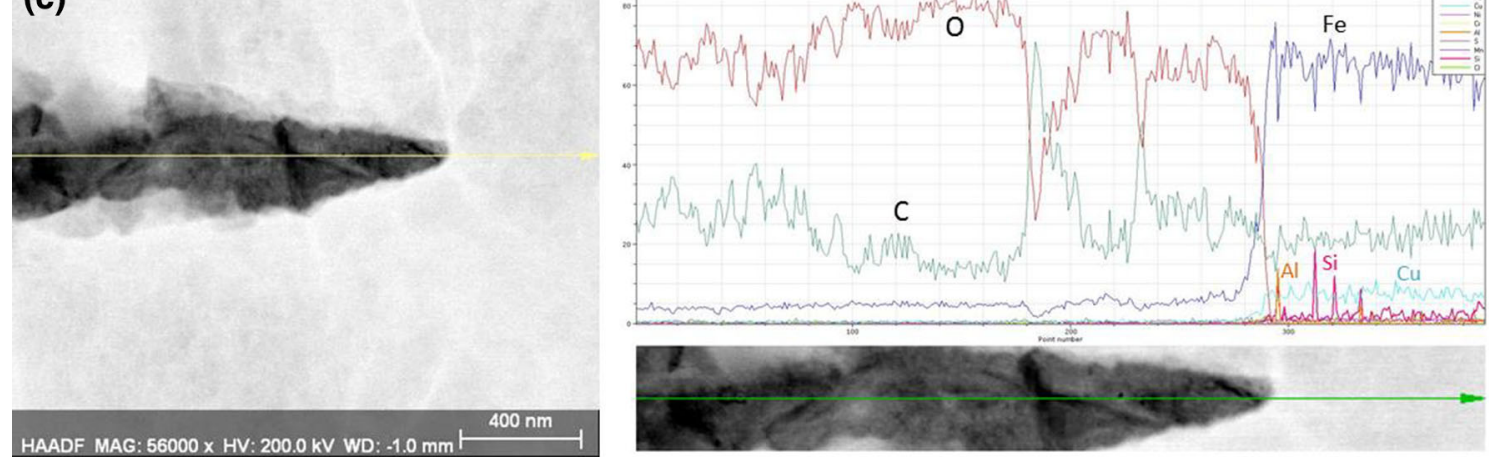

Fig. 14 TEM micrographs showing an SCC crack in X80 after 220 days testing: a TEM bright field image showing a well propagated crack; b TEM bright field showing the crack tip having a sub-grain boundary initiated at crack tip; c STEM-HAADF image of the crack tip along with EDS line scan results showing concentration of $C, O, A l$ and $S i$ along the crack and at crack tip 